\title{
Adaptive mechanical tolerance and dislodgement velocity of the kelp Laminaria japonica in wave-induced water motion
}

\author{
Shigeru Kawamata* \\ National Research Institute of Fisheries Engineering, Ebidai, Hasaki, Kashima, Ibaraki 314-0421, Japan
}

\begin{abstract}
Adaptive mechanical tolerance of Laminaria japonica to water motion was examined by field transplant and laboratory flow-tank experiments. L. japonica attaching to plastic plates were obtained at mid-water platforms sheltered from and moderately exposed to wave action. The environmental water velocities were determined during the cultivation period and transplant experiment using ultrasonic flow meters and available offshore wave height records. When transplanted to 3 depth sites with different intensities of wave-induced water motion, almost all the 'sheltered' plants were dislodged from the plastic plates by waves within $5 \mathrm{~d}$, while most of the 'exposed' ones remained attached even at the shallowest depth $72 \mathrm{~d}$ after transplantation. This difference in mechanical tolerance was quantified by a flow-tank experiment conducted in sinusoidal oscillatory flows: $50 \%$ of the 'sheltered' plants were dislodged at a velocity amplitude of 0.8 to $0.9 \mathrm{~m} \mathrm{~s}^{-1}$, while all of the 'exposed' plants persisted even at $1.1 \mathrm{~m} \mathrm{~s}^{-1}$. The maximum water velocities encountered by the transplants were estimated using ultrasonic flow meter records and the period-averaged water speeds, which were determined by correlating water velocity with decreased mass of gypsum blocks. These estimates coupled with the observed survivorships at the transplant sites were consistent with the results of the flow-tank experiment. Attachment strength increased significantly as the holdfast grew for the 'exposed' plants but was constant for the 'sheltered' ones. In addition, the 'sheltered' plants had a short, wide, undulated blade which resulted in higher drag while the 'exposed' plants had a long, narrow, flat blade and thereby lower drag. Despite the marked difference in tolerance to water motion, the frequency distribution of the root-mean-square water velocity experienced by plants during the growth period was only $0.05 \mathrm{~m} \mathrm{~s}^{-1}$ higher at the exposed culture station than at the sheltered one, suggesting the presence of a critical velocity in developing the adaptive mechanical tolerance. The observed dislodgement velocity for the 'sheltered' plants was considerably lower than predicted from general hydrodynamic theories describing attachment strength of a thallus stretched out in the direction of flow. This indicates that detailed dynamic behaviors of plants should be explored to predict the wave-induced mechanical failure in large, flexible algae such as L. japonica.
\end{abstract}

KEY WORDS: Adaptation · Attachment strength $\cdot$ Drag $\cdot$ Kelp $\cdot$ Velocity measurement $\cdot$ Wave exposure

Resale or republication not permitted without written consent of the publisher

\section{INTRODUCTION}

Adaptive change in morphology and anatomy in response to mechanical stress is a common phenomenon in plants and animals. The ecological importance of mechanical adaptation is that it allows species to

\footnotetext{
*E-mail: matasan@nrife.affrc.go.jp
}

expand or shift their distributions along environmental gradients, thereby improving survivorship, growth, or reproduction (Kitching et al. 1966, Palumbi 1986, Boulding \& Van Alstyne 1993, Trussell 1997). Thus investigations of developmental and adaptive growth responses to the mechanical stresses experienced are necessary for understanding the distributional limits of species. 
Benthic marine plants inhabiting nearshore coastal areas exhibit marked morphological differences in response to the degree of wave exposure. Many macroalgae with a long leaf-like thallus have a wide, thin, undulate blade at sheltered sites and a narrow, thick, flat blade at exposed sites (Sundene 1964, Gerard \& Mann 1979, Koehl 1986). The high surface area:mass ratio of the blade for 'sheltered' plants enhances the absorption of light and dissolved nutrients (Gerard \& Mann 1979). In addition, their undulate morphology might increase the blade movement in low water velocities, thereby reducing the surface boundary layer and increasing the nutrient uptake (Norton et al. 1982, Koehl \& Alberte 1988). 'Sheltered' plants thus can sustain high productivity in low water velocities. However, the sheltered blade form imposes increased hydrodynamic force on the alga as well as decreased structural strength. 'Sheltered' plants might be ripped off from the substratum when transplanted to an exposed site, while 'exposed' plants moved to a sheltered site can survive and produce new blade tissue morphologically similar to 'sheltered' ones (Norton 1969, Gerard \& Mann 1979). Thus the formation of the exposed blade morphology might result from the functional adaptation to water motion. This functional adaptation might begin to develop when a plant is subjected to an external force greater than some critical level. As demonstrated by Gerard (1987), the application of static tension to cultured plants can result in the 'exposed' blade form, while in the absence of tension short, wide, 'sheltered' blades form. Tenacity of adhesion may also develop in response to water motion since plants grown in calm waters are often poorly attached (Norton et al. 1982).

Despite such knowledge on mechanical adaptation of marine plants, the quantification of how and to what extent organisms are adapted to water motion is very difficult due to the exceptionally complex nature of nearshore coastal water motion in the field. Technically the measurement of water velocity with a high frequency and accuracy is possible in subtidal areas using precision instruments such as electromagnetic and ultrasonic flow meters. However, these instruments are expensive and thus difficult to employ in sufficient numbers in the field. Alternatively, a practical technique using gypsum blocks (Muss 1968, Doty 1971, Glenn \& Doty 1992) has often been used. Gypsum blocks dissolve in water at a rate which increases with water motion, and thus has the potential for providing a measure of the cumulative water speed (Thompson \& Glenn 1994). The materials are easily constructed and inexpensive, and therefore can be deployed in large numbers in rocky habitats. Nevertheless, the calibration of gypsum blocks has solely been performed under simplified flow conditions in the laboratory and no studies have tested them in complex water motions in the field by comparing them with simultaneous high-frequency measurements from flow meters.

There are many species in the genus Laminaria, such as $L$. japonica in this study, which attach to the substratum with a relatively small holdfast compared to the large blade. L. japonica commonly occurs from sheltered bays to open sites exposed to strong wave action, along the northern coast of Japan. This species has an undivided lamina, a single stipe and a branched holdfast. Although the morphological variations between $L$. japonica populations from different habitats have been shown to be heritable (Sanbonsuga \& Torii 1973), little information is available on their phenotypic plasticity to water motion.

The aim of this study was to reveal the relationship between water motion and the mechanical adaptation of Laminaria japonica, and how far the adaptive tolerance might develop in response to temporally varying degrees of water motion in the field. 'Sheltered' and 'exposed' plants were cultivated at stations where the water velocity was observed over the growth period. Tolerance to water motion was then examined by a transplantation experiment in the field and by a flowtank experiment in the laboratory. Mechanical failure of an alga has generally been predicted from simple empirical equations describing the hydrodynamic force exerted on the thallus stretched in the direction of flow and the breaking strength of stipe or holdfast (Charters et al. 1969, Koehl 1986, Seymour et al. 1989, Carrington 1990, Gaylord et al. 1994, Blanchette 1997). However, this method of predicting the mechanical failure does not include little known mechanical forces associated with plant's dynamic motion under waves, such as stress concentrations and impulsive forces, and no studies have compared the predictions and observations with direct measurements of water velocities. In this study the observed critical velocity for mechanical failure was compared with predictions using previous method of empirical equations.

\section{METHODS}

Cultivation of Laminaria japonica. 'Sheltered' and 'exposed' plants of Laminaria japonica were obtained from culture in Samenoura Bay on the northeastern Pacific coast of Honshu, Japan $\left(38^{\circ} 22^{\prime} \mathrm{N}, 141^{\circ} 29^{\prime}\right.$ and $30^{\prime}$ E) (Fig. 1). Strings with seedling sporophytes attached were available, which were produced using a common technique for cultivating Laminaria (Hasegawa 1971a). The strings were twisted around $10 \mathrm{~mm}$ thick, $12 \times 12 \mathrm{~cm}$ square polyvinyl chloride (PVC) plates. Ten plates were fixed along the sides of a $1 \times$ 
$0.25 \mathrm{~m}$ steel frame. Two frames were horizontally buoyed $2 \mathrm{~m}$ below mean sea level (MSL) at each of 2 sites with different wave exposures in Samenoura Bay. One site was $5 \mathrm{~m}$ deep and located in the most sheltered innermost part of the bay, and the other was a $9 \mathrm{~m}$ deep nearshore site closer to the bay mouth moderately exposed to ocean waves. The culture was initiated in late December 1995.

The above method of cultivation had 2 advantages. First, the cultured sporophytes were obtained from the same parent plants so that any heritable differences in morphology would be minimal. In addition, the environmental water motion at the floating culture was less complex than that on irregular natural habitats, thereby facilitating the determination of the water velocity.

Transplant experiment. The 'sheltered' and 'exposed' plants were transplanted from the culture stations to a moderately exposed rocky slope on a shore

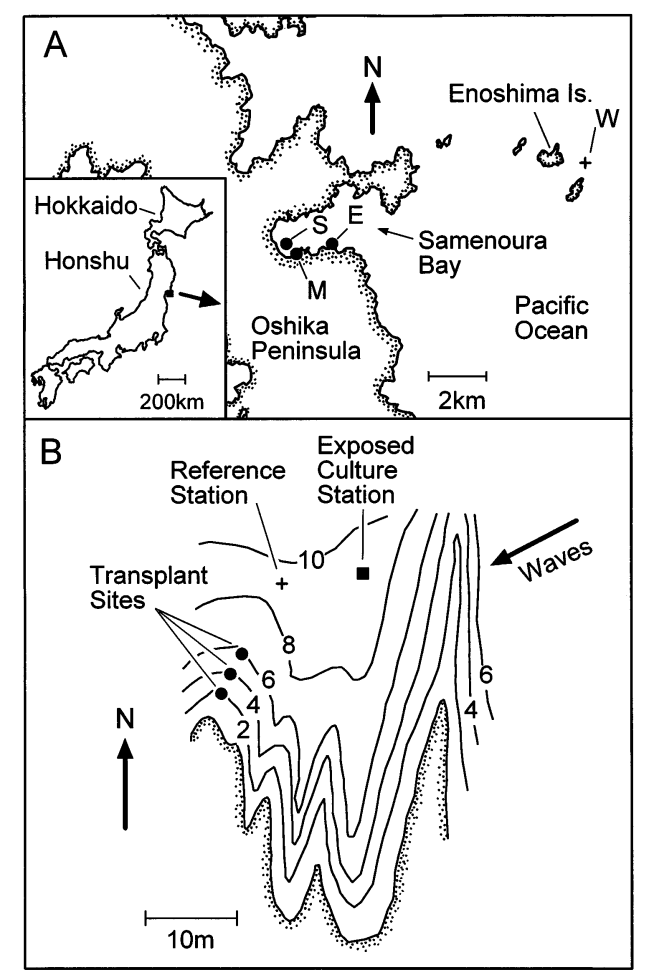

Fig. 1. (A) Map of Samenoura Bay, Japan, showing locations of study sites. (B) Map of sites around the exposed culture station. S: sheltered, E: exposed culture stations; M: natural habitat where measurements were made of the attachment strength; W: deployment site of wave gauge. Depth contours are in $\mathrm{m}$ near the exposed culture station on 29 May 1996 (Fig. 1B). The bedrock is rugged and slopes steeply from the shore to a depth of $6 \mathrm{~m}$ within $10 \mathrm{~m}$ of the shoreline. The transplant depths were approximately 2, 4, and $6 \mathrm{~m}$ below MSL. The initial plants overgrowing the plates were too numerous to count (probably more than 100). To simplify the subsequent observations of survivorship, the plants were haphazardly thinned out by carefully cutting the stipes with scissors down to 14-27 plants per plate. Blade length and width were measured for 10 randomly sampled individuals on each plate, and the entire wet mass of plants on the plates was weighed with a scale to the nearest of $0.1 \mathrm{~kg}$ (Table 1). Two overgrown plates from each culture station were fixed at each transplant depth with anchor bolts, which were embedded into the bedrock using an underwater drill.

The plants remaining on the plates were counted and occasionally weighed on a boat and then were returned to the slope 5,12, 23 and $72 \mathrm{~d}$ after transplantation. During examinations the time exposed to the air was minimized to ensure minimal stress to the plants during the course of the experiment. The transplant slope was a typical 'barren ground', on which the sea urchins Strongylocentrotus nudus were dominant. Conspicuous herbivorous animals were periodically removed to prevent grazing on the transplants during the course of the experiment.

Laboratory flow-tolerance experiment. On the day after the transplantation, cultured plants were transported to the Hokkaido Central Fisheries Experimental Station (HCFES), Yoichi, Hokkaido, to examine the tolerance to oscillatory flows in a laboratory flow tank. Plants attached to plates were thinned out as in the transplant experiment, and were then packed in expanded polystyrene containers and sent by air within $24 \mathrm{~h}$, the temperature being maintained at approximately $5^{\circ} \mathrm{C}$. The plants sent to HCFES were maintained in running seawater and all experiments were conducted within $6 \mathrm{~d}$ of arrival. 
Flow-tolerance experiments were made using a large recirculating flow tank with a $8 \mathrm{~m}$ long $\times 1.5 \mathrm{~m}$ wide $\times 1 \mathrm{~m}$ high working section. The tank is equipped with 2 pairs of reversible propellers to produce oscillating flows. Plates overgrown by plants were fixed to the bottom in the working section of the tank, and then a sinusoidal oscillatory flow was produced with a cyclic period of $12.8 \mathrm{~s}$. After 20 to 120 min experimental runs at a given water velocity, the plants remaining on the plates were counted. This procedure was repeated with an increasing velocity amplitude until the maximum velocity capability of the tank $\left(=1.1 \mathrm{~m} \mathrm{~s}^{-1}\right)$ was reached.

Measurement of morphology and attachment strength. Morphological characteristics and attachment strength were measured for the plants sent to HCFES. Undulation of kelp blades occurred mainly on the lateral peripheral parts of the blades, while the thicker median portion was flat, even for 'sheltered' plants. Thus the undulation index was defined as the ratio of the averaged length of the lateral fringes to the length of the blade centerline. In this study, tattered distal ends and rounded or cuneate proximal ends were removed from the blade, and then the peripheral and median lengths of the truncated blade were determined by carving 2 strips of blade from the margins and 1 from the center. The width of the blade at the broadest cross section was measured to the nearest $1 \mathrm{~mm}$, and the thickness at the center was measured with a micrometer to the nearest $0.001 \mathrm{~mm}$. The attachment strength of the plants was determined as follows: The overgrown plate was vertically fixed to a rigid support, and then water was added to a bucket suspended with a string from the stipe of a plant until the plant broke. The holdfasts of the plants tested were dislodged almost intact. The weight (including the plant itself) loaded when the plant detached, and the wet mass of the holdfast blotted dry was then measured with an electronic balance to the nearest $0.01 \mathrm{~g}$.

Attachment strength was also measured in the field on 21 June 1996 for Laminaria japonica plants continuously cultivated on the exposed and sheltered platforms and for wild plants inhabiting a rocky shallow subtidal site. To determine the strength, a string attached to a $10 \mathrm{~kg}$ spring scale that recorded the maximum force was knotted around a stipe and then pulled parallel to the substratum until the holdfast was dislodged.

Determination of field water velocity. High-frequency measurements were made of the horizontal water velocity vector in the field using 2-dimensional ultrasonic flow meters with a built-in thermometer (Tsurumi-Seiki Co., Yokohama, model AICM-2F). The water velocity was sampled in the burst mode: 512 samples spaced at $0.5 \mathrm{~s}$ intervals were recorded at $2 \mathrm{~h}$ intervals (here referred to as the burst time intervals to distinguish from the former sampling time intervals), while the temperature was recorded once during each burst time interval. However, because of difficulties in maintaining the flow meters at the mid-water culture platforms throughout the cultivation period and in fixing them at the transplant sites, the following practical procedures were employed to estimate the water velocity encountered by the cultured and the transplanted Laminaria japonica. During cultivation and the transplant experiment, comparable water velocities were observed by fixing an ultrasonic flow meter on the bottom of the transplant slope (hereafter called the reference station; Fig. 1B). Afterwards, to estimate the water velocity at the culture stations and at the transplant sites from the velocity observed at the reference station, velocity relationships between the localities were determined by simultaneous observations with 3 ultrasonic flow meters and gypsum blocks. When a flow meter was deployed at each of the 2 culture stations and at the reference station, gypsum blocks were deployed at the 3 flow meters for calibration as well as at the 3 transplant depths. Seven- or 3-d measurements were repeated 4 times by replacing the gypsum blocks while the ultrasonic flow meters were working. Simultaneous observations were conducted from January to February 1997, and from January to February 1998.

The gypsum blocks were specially made to determine the time-averaged rate of bottom water motion for approximately $1 \mathrm{wk}$ in moderate turbulence conditions. Two sorts of plaster of Paris were used: Special Grade and High Stone (Yoshino Sekko Co., Tokyo). Special Grade is a normal plaster of Paris $\left(\mathrm{CaSO}_{4} \cdot \frac{1}{2} \mathrm{H}_{2} \mathrm{O}\right)$, and blocks made of it alone are too soluble for the aims of this study. On the other hand hemispheres of High Stone, which contain plastic ingredients, are insoluble but easily deformed when immersed in water. Preliminary tests showed that the 'best' gypsum block was made of 56:14:30 mixture of Special Grade, High Stone and distilled water. This was thoroughly stirred in a round plastic bowl, and then the bowl was vigorously tapped and rocked to remove all air bubbles. A hemispherical mould of $50 \mathrm{~mm}$ diameter, which was made in a plastic column of $35 \mathrm{~mm}$ height and $70 \mathrm{~mm}$ diameter, was filled carefully with the gypsum to ensure no air bubbles were included and set aside for $24 \mathrm{~h}$ at room temperature to harden. After hardening, the gypsum was shaved using the edge of a stainless steel ruler so that it was flush with the top surface of the mould. The complete gypsum hemisphere was removed from the mould by repeatedly rapping the edge of the mould against a concrete floor. Gypsum blocks were dried in warm air 
over $5 \mathrm{~d}$ until their weights were constant. Blocks were glued with a silicon sealant to $12 \times 12 \mathrm{~cm}$ PVC base plates for application.

Because complete time-series velocity measurements could not be obtained at the reference station, the offshore wave heights at the nearest wave observatory of the Japan Meteorological Agency were used to estimate them. The data were of significant wave heights observed with an ultrasonic-type wave gauge every hour at a depth of $57 \mathrm{~m}$ off Enoshima Island $\left(38^{\circ} 23^{\prime} 40^{\prime \prime} \mathrm{N}, 141^{\circ} 36^{\prime} 37^{\prime \prime} \mathrm{E}\right)$, about $9 \mathrm{~km}$ east of the reference station (Fig. 1). At such a deep depth, however, this type of gauge measured directly the seasurface elevation so that wind-driven waves, which might influence in shallow waters, could be observed as swell. The below-described root-mean-square (rms) water velocity at the reference station was estimated using a power regression equation fitted to the wave heights using the log-log transformed data.

Analysis of water velocity. To evaluate the mechanical effect of the complex nearshore water motion on attached organisms, the rms water velocity, $U_{\mathrm{rms}}$ is used as a 'best' measure of the time-averaged degree of water motion, because in general, the hydrodynamic force on an object is proportional to the square of the water velocity. The square of $U_{\text {rms }}$ can be divided into the mean and fluctuating parts:

$$
U_{\mathrm{rms}}^{2}=U_{\mathrm{m}}^{2}+U_{\mathrm{rms}}^{\prime}{ }^{2}
$$

where $U_{\mathrm{m}}$ and $U_{\text {rms }}^{\prime}$ are the magnitude of the mean velocity vector and the rms of the velocity fluctuations. In addition to $U_{\text {rms }}, U_{\mathrm{m}}$ and $U_{\text {rms }}^{\prime}$, the mean water speed (or the average of the absolute water velocity) $U_{\text {abs }}$ which is involved in the dissolution rate of gypsum blocks as described later, was calculated for all timeseries data from the ultrasonic flow meters. Symbols are defined and data procedure is described in Appendices A and B, respectively.

Estimation of maximum water speed at transplant sites. The wave-induced velocity amplitude randomly varies with time. At nearshore subtidal sites such as the transplant ones, however, the most probable value of the maximum velocity amplitude in a burst time interval $\Delta \tau$, denoted by $<\hat{U}_{\max }>$, is approximated by

$$
<\hat{U}_{\max }>\approx\left[2 \ln \left(1.2 \Delta \tau / T_{\mathrm{s}}\right)\right]^{1 / 2} U_{\mathrm{rms}}
$$

where $T_{\mathrm{s}}$ is the significant wave period (see Appendix B). Since the transplant sites and reference station were close neighbours on the same slope, the prevailing waves will travel across the slope with little energy dissipation due to breaking. I thus assumed that $U_{\text {rms }}$ at a depth on the slope varied in proportion to that at the reference station $\left(U_{\text {rms, ref. }}\right)$, that is,

$$
U_{\text {rms }} / U_{\text {rms, ref. }}=f(h)
$$

where $f$ is the function of the temporal water depth $h$, which is modified by the tide. Although the function is non-linear, a good approximation can be obtained from gypsum-block data as

$$
f(\bar{h}) \approx \bar{U}_{\text {abs }} / \bar{U}_{\text {abs, ref. }}
$$

where $\bar{U}_{\text {abs }}$ is the overall average of the water speed while a gypsum block is deployed at the mean water depth $(\bar{h})$ and $\bar{U}_{\text {abs, ref. }}$ is the $\bar{U}_{\text {abs }}$ observed simultaneously at the reference station (Appendix C). The $\bar{U}_{\mathrm{abs}}$ was given by

$$
\bar{U}_{\mathrm{abs}}=C\left(\bar{R}-R_{0}\right)
$$

with

$$
\bar{R}=\left(d_{0} / 2\right)\left[1-\left(m_{\tau} / m_{0}\right)^{1 / 3}\right] / \tau
$$

where $d_{0}$ is the initial diameter of the gypsum hemisphere, $\tau$ is the period of measurement, and $m_{0}$ and $m_{\tau}$ are the initial and final masses, respectively (see Appendix D). The coefficients $C$ and $R_{0}$ were determined by fitting Eq. (5) to the $\bar{U}_{\text {abs }}$ and $\bar{R}$-measurements from the ultrasonic flow meters and attached gypsum blocks.

Measurement of the drag on various blade forms. Measurements were made of the drag force on various blade forms of Laminaria plants in steady flows to establish general formulas of the drag. Plants used were collected from sites with different degrees of wave exposure in Oshoro Bay on the western coast of Hokkaido $\left(43^{\circ} 12^{\prime} \mathrm{N}, 140^{\circ} 51^{\circ} \mathrm{E}\right)$ in late June 1999 and obtained from culture in a laboratory tank. Laminaria plants inhabiting Oshoro Bay are traditionally referred to as L. religiosa Miyabe and usually possess narrower blades than typical L. japonica plants. However, cross fertilization trials between $L$. japonica and L. religiosa have been found to be completely fertile (Yabu 1964), and both species were considered to be ecads by Hasegawa (1971b). In this paper, I follow the opinion of Hasegawa (1971b) and consider the plants from Oshoro Bay to be L. japonica. Specimens $(N=20)$ from Oshoro Bay included various blade forms from extremely 'exposed' types of narrow strap-like blades to wide 'sheltered' ones with a somewhat corrugated marginal frill similar to typical blades of $L$. japonica. Extremely 'sheltered' plants $(N=9)$ with marked corrugation were obtained from culture (juvenile sporophytes of $L$. japonica which naturally settled onto $10 \mathrm{~mm}$ thick, $15 \times 15 \mathrm{~cm}$ square plastic plates hung in Samenoura Bay), and then the plants attached to the plates were fixed to the bottom of a $6 \times 0.6 \times 1 \mathrm{~m}$ test flume of a recirculating flow tank at the National Research Institute of Fisheries Engineering (NRIFE). A computer-controlled reversible propeller in the tank produced standing free-surface water waves like field swells. Illuminated continuously with metal halide 


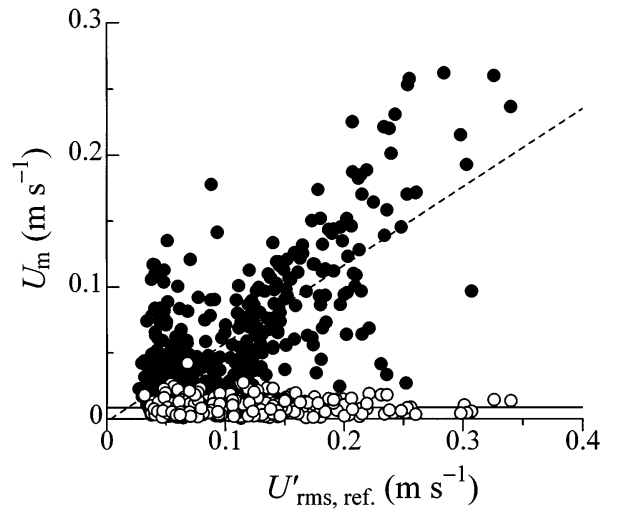

Fig. 2. Relationships between the magnitude of the mean velocity vector $\left(U_{\mathrm{m}}\right)$ at the sheltered $(0)$ and the exposed $(\bullet)$ culture stations and the rms velocity fluctuations at the reference station $\left(U_{\text {rms, ref. }}^{\prime}\right)$, which were measured by ultrasonic flow meters during the simultaneous observations. Solid line represents least squares regression for the sheltered culture station: $U_{\mathrm{m}}=0.0085+0.000234 U_{\text {rms, ref., }}^{\prime}\left(\mathrm{r}^{2}=0.00537, N=\right.$ 362 , not significant at $\mathrm{p}=0.05$ ) while dashed line represents the regression for the exposed station: $U_{\mathrm{m}}=-0.0019+$ $0.5926 U_{\text {rms, ref. }}^{\prime}\left(\mathrm{r}^{2}=0.540, N=492, \mathrm{p} \ll 0.001\right)$

lamps, the sporophytes were grown in the oscillatory flow caused by the waves from late March to late June, 1999. The water depth was $0.40 \mathrm{~m}$ and the seawater temperature was maintained at about $15^{\circ} \mathrm{C}$ throughout the cultivation. The local velocity amplitude varied along the test flume from 0.033 to $0.206 \mathrm{~m} \mathrm{~s}^{-1}$ at a cyclic period of $12 \mathrm{~s}$. The light intensities at the plant blade surface were almost uniform $\left(119 \pm 15.0 \mu \mathrm{E} \mathrm{m}{ }^{-2} \mathrm{~s}^{-1}\right)$. About $6 \mathrm{~m}^{3}$ seawater in the tank was partially renewed with fresh seawater periodically to supply nutrients.

Drag on individual plants undulating in steady flow was measured using another large recirculating flow tank with a $6 \times 2.0 \times 1.1 \mathrm{~m}$ working section in NRIFE. A plant was attached at its stipe to a tension gauge (SSK Co., Tokyo, Model LT10-10) which was held firmly in the middle of the working section of the tank. Drag data were sampled for each plant in different water velocities from 0.2 to $1.9 \mathrm{~m} \mathrm{~s}^{-1}$, which were simultaneously measured using an electromagnetic flow meter (KENEK Co., Tokyo, Model MV-201H) fixed upstream of the tension gauge.
The drag coefficient, $C_{\mathrm{d}}$, was calculated as

$$
C_{\mathrm{d}}=2 F_{\mathrm{d}} /\left(\rho S U^{2}\right)
$$

where $F_{\mathrm{d}}$ is the drag, $\rho$ the density of the fluid, $S$ the wetted surface area of the object, and $U$ the water velocity. In general drag coefficients of algae vary with several factors including the water velocity and thallus size (Carrington 1990, Friedland \& Denny 1995). For a rigid, smooth, flat plate oriented parallel to the flow, the drag coefficient is represented by an empirical equation (Schlichting 1968):

$$
C_{\mathrm{d}}=3.91(\ln R e)^{-2.58}
$$

Here $R e$ is the Reynolds number defined as

$$
R e=\rho U l / \eta
$$

where $l$ is the length of the object along the flow, and $\eta$ the dynamic viscosity of the fluid. By analogy, given $S$ as twice the planform area of a blade, $C_{\mathrm{d}}$ for a single plate-like blade such as Laminaria japonica was expected to be described as a function of $R e$.

The planform area of each blade was measured as follows. The blade was photocopied with a ruler while pressed flat using transparent, thick acrylic plastic boards. The blade image was then outlined using a digitizer to compute its area.

\section{RESULTS}

\section{Water velocity at the culture stations}

Velocity measurements from the ultrasonic flow meters indicated that the water motion at both culture stations was caused primarily by waves. At the sheltered station, the mean velocity $U_{\mathrm{m}}$ was small $(95 \%$ of $U_{\mathrm{m}}<0.02 \mathrm{~m} \mathrm{~s}^{-1}$ ) and $U_{\text {rms }}^{\prime}{ }^{2}$ amounted to $99.5 \%$ of $U_{\mathrm{rms}}{ }^{2}$. At the exposed station, the average ratio of $U_{\mathrm{rms}}{ }^{2}$ to $U_{\mathrm{rms}}{ }^{2}$ was somewhat lower $(82.0 \%)$, but $U_{\mathrm{m}}$ increased with the increasing $U^{\prime}$ ms at the reference

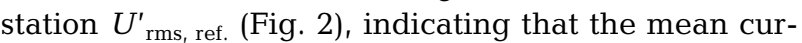
rent was also driven by waves, which probably broke at an immediately offshore rock elevation (Fig. 1B). $U_{\text {rms }}$ at both culture stations was closely associated with $U_{\text {rms, ref. }}$ (Table 2). The time variation in the

\begin{tabular}{|c|c|c|c|}
\hline Regression equation & $N$ & $\mathrm{r}^{2}$ & SE \\
\hline $\ln \left(U_{\mathrm{rms}}\right.$ at sheltered station $)=-0.214+0.8296 \ln U_{\mathrm{rms}}$ ref. & 362 & 0.752 & 0.218 \\
\hline $\ln \left(U_{\mathrm{rms}}\right.$ at exposed station $)=-0.244+0.6729 \ln U_{\mathrm{rms}, \text { ref. }}$ & 492 & 0.922 & 0.110 \\
\hline $\ln \left(U_{\text {rms, ref. }}\right)=-2.579+0.8495 \ln H_{\mathrm{s}}$ & 1043 & 0.650 & 0.2713 \\
\hline
\end{tabular}

Table 2. Least squares regressions fitted to the relationships between the $U_{\mathrm{rms}}\left(\mathrm{m} \mathrm{s}^{-1}\right)$ at the culture stations and that at the reference station $U_{\mathrm{rms}}$, ref. $\left(\mathrm{m} \mathrm{s}^{-1}\right)$ and between the $U_{\mathrm{rms}, \text { ref. }}$ and the offshore significant wave height $H_{\mathrm{s}}(\mathrm{m})$ 


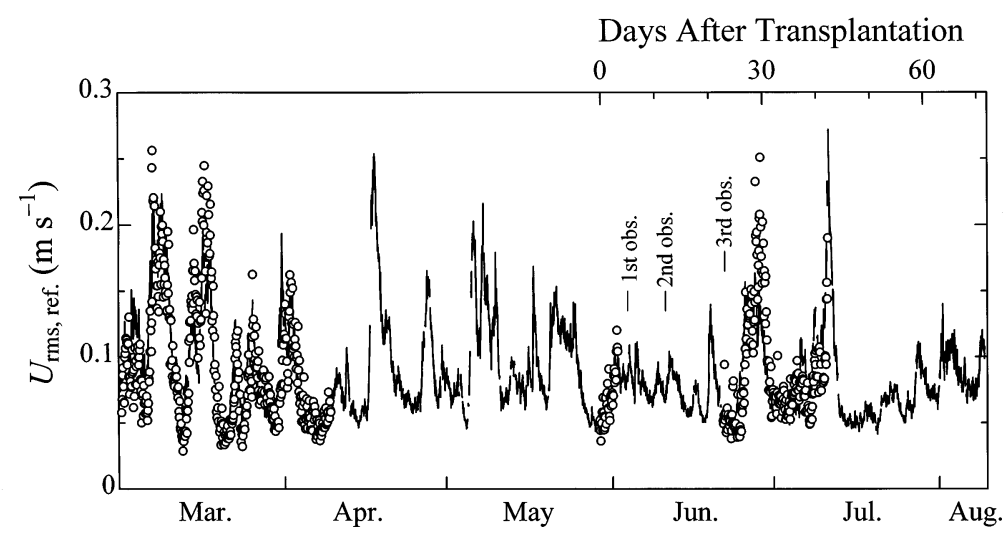

Fig. 3. Temporal variation in the rms water velocity at the reference station $\left(U_{\mathrm{rms}, \text { ref. }}\right)$ in the last $3 \mathrm{~m}$ of cultivation and the subsequent transplant experiment in 1996. (o) Measurements from ultrasonic flow meters. Line represents the predictions from the offshore wave height records using the regression equation described in Table 2 . Times of observations on the survivorship of the transplants are shown

\section{Survivorship at the transplant sites}

The transplant experiment in the field showed a striking difference in the tolerance to waves between plants from the sheltered station and ones from the exposed station (Figs. $5 \& 6$ ). All 'sheltered' plants except for 2 at the 2 and $4 \mathrm{~m}$ deep transplant sites were removed from the substrates by waves in the first $5 \mathrm{~d}$ of the experiment, and these remaining plants were tattered and reduced to $<0.3 \mathrm{~m}$ in blade length. Until that time most of the 'sheltered' plants survived at the $6 \mathrm{~m}$ deep site which was subject to lowest water motion, but the specimens remaining declined over time both in number and in mass. Although 'sheltered' plants appeared
$U_{\text {rms, ref. }}$ estimated from the offshore significant wave height records $\left(H_{\mathrm{s}}\right)$ using the regression equation described in Table 2 showed good agreement with the observations (Fig. 3). Similar magnitudes of waveinduced water velocity occurred periodically at $\sim 10 \mathrm{~d}$ intervals over a period of 3 mo prior to the transplantation, when the culture plants grew rapidly. Thus the frequency distributions of the $U_{\text {rms }}$ experienced by plants growing at the sheltered and exposed culture platforms corresponded with those estimated from the

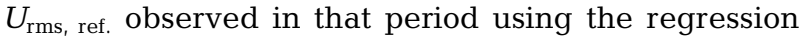
equations. Note that $U_{\text {rms }}$ at the exposed culture station as a whole was only $0.05 \mathrm{~m} \mathrm{~s}^{-1}$ larger than that at the sheltered station (Fig. 4).



Fig. 4. Estimated frequency distribution of the rms water velocity $\left(U_{\text {rms }}\right)$ encountered by Laminaria japonica growing at the sheltered (thin line) and the exposed (bold line) culture stations. Vertical axis represents the percent frequency of $>U_{\text {rms }}$

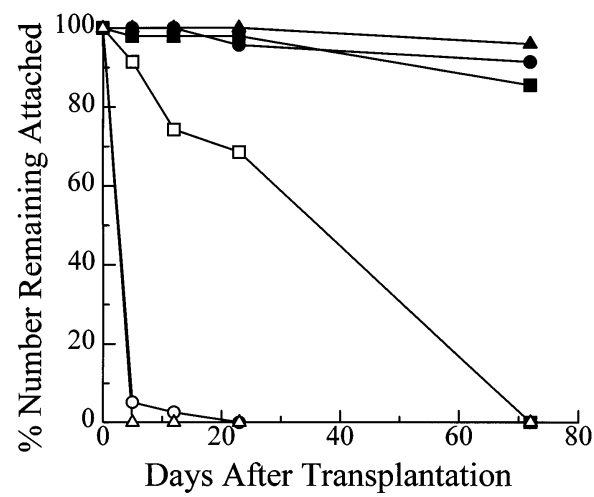

Fig. 5. Survivorships of the 'sheltered' (open symbols) and the 'exposed' (closed symbols) Laminaria japonica transplanted to depths of 2 (circles), 4 (triangles) and $6 \mathrm{~m}$ (squares) below mean sea level (MSL) on a moderately exposed rocky slope

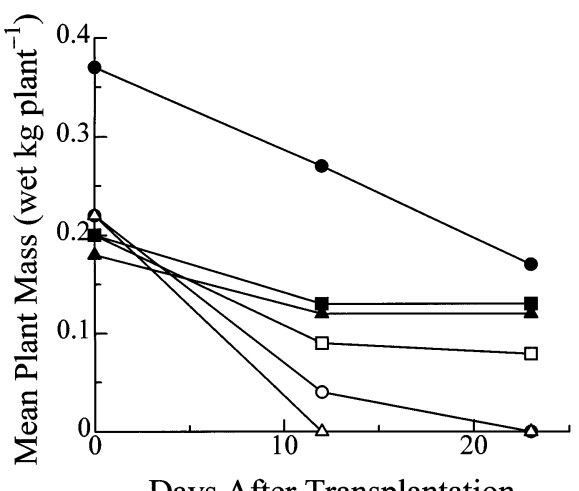

Days After Transplantation

Fig. 6. Reduction in the mean plant wet mass of 'sheltered' (open symbols) and 'exposed' (closed symbols) Laminaria japonica transplanted to depths of 2 (circles), 4 (triangles) and $6 \mathrm{~m}$ (squares) below MSL on a moderately exposed rocky slope 


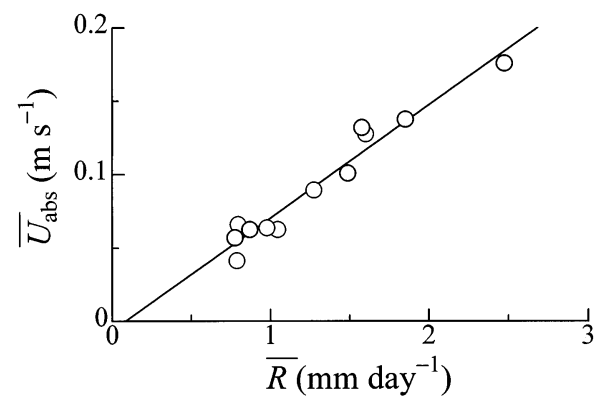

Fig. 7. Relationship between the overall average of dissolution rate $(\bar{R})$ of gypsum blocks and the overall average of the simultaneous measurements of the water speed ( $\left.U_{\text {abs }}\right)$ from ultrasonic flow meters. Line represents least squares regression: $\bar{U}_{\mathrm{abs}}=0.0769(\bar{R}-0.084),\left(\mathrm{r}^{2}=0.948, N=12, \mathrm{SE}=\right.$ $0.010 \mathrm{~m} \mathrm{~s}^{-1}$ )

to have been once adapted to the new flow environment at the $6 \mathrm{~m}$ deep site within $12 \mathrm{~d}$ by losing more than half of their initial blade mass, finally all of them were removed from the substrates during the period of subsequent rapid wave-induced water motion (Fig. 3). In contrast, most of the 'exposed' plants survived throughout the experiment, even at the shallowest depth. The surviving plants were reduced in length at all depths, probably because of abrasion on the rugged rock surface. Such breakage appeared to last until the blade length (approximated from photographs) was as short as 0.4 to $0.5 \mathrm{~m}$.

\section{Estimated water velocity at transplant sites}

Simultaneous observations using ultrasonic flow meters with gypsum blocks attached showed that the environmental seawater temperature was almost constant (mean: $8.6^{\circ} \mathrm{C}$, range: 7.07 to $9.50^{\circ} \mathrm{C}$ ) and that the mean dissolution rate $(\bar{R})$ of the gypsum block was closely correlated with the overall average of the water speed $\left(\bar{U}_{\text {abs }}\right)$ measured simultaneously by the ultrasonic flow meters (Fig. 7). Also, the salinity varies little in Samenoura Bay in winter, so that the environmental salinity was probably identical to 34 ppt observed by Sasaki (unpubl.) in the bay on 13 January 1997. Thus the linear least squares regression fit to the data ( $\bar{U}_{\text {abs }}$ in $\mathrm{m} \mathrm{s}^{-1}$ and $\bar{R}$ in $\mathrm{mm} \mathrm{d}^{-1}$ ):

$$
\begin{gathered}
\bar{U}_{\mathrm{abs}}=0.0769(\bar{R}-0.084) \\
\left(r^{2}=0.948, N=12, \mathrm{SE}=0.010 \mathrm{~m} \mathrm{~s}^{-1}\right)
\end{gathered}
$$

will provide adequate $\bar{U}_{\text {abs }}$-estimates at the transplant site where the gypsum blocks were deployed in the simultaneous observations. The ratios of the $\bar{U}_{\text {abs }}$ at the transplant depths of 2, 4 and $6 \mathrm{~m}$ to that at the reference station ( $\bar{U}_{\mathrm{abs}, \text { ref. }}$ ) were approximately constants of 2.83, 2.17 and 1.64, respectively (Table 3 ). These ratios, approximating $f$, indicated a non-linear increase with decreasing depth (Fig. 8). In this paper, the function of $f$ was empirically determined by fitting the data to the exponential equation that intersected the point of $(h=$ $9 \mathrm{~m}, f=1$ ) as

$$
f(h)=\mathrm{e}^{-0.1506(h-9)}
$$

Using Eqs. (10) \& (11), the maximum water speed which occurred at each transplant depth in the first rough sea period when most 'sheltered' plants were dislodged can be estimated as follows: The $U_{\text {rms }}$-predictions from the offshore wave heights indicated that the $3.5 \mathrm{~d}$ records from the first ultrasonic flow meter in the transplant experiment included the highest water speed until the first survivorship observations $5 \mathrm{~d}$ later

Table 3. Results of water speed measurements at transplant depths using gypsum blocks. Simultaneous measurements were repeated 4 times: 24 to 31 January 1997 (I), 31 January to 7 February 1997 (II), 23 to 26 January 1998 (III), 26 to 30 January 1998

\begin{tabular}{|c|c|c|c|c|c|c|c|}
\hline $\begin{array}{l}\text { Depth } \\
\text { (m) }\end{array}$ & Period & $\begin{array}{l}m_{0} \\
(g)\end{array}$ & $\begin{array}{l}m_{\tau} \\
(g)\end{array}$ & $\begin{array}{c}\tau \\
(\mathrm{d})\end{array}$ & $\begin{array}{c}\bar{U}_{\text {abs }} \\
\left(\mathrm{m} \mathrm{s}^{-1}\right)\end{array}$ & $\bar{U}_{\text {abs }} / \bar{U}_{\text {abs, ref. }}$ & $\begin{array}{c}\text { Mean ( } \pm \text { SD) of } \\
\bar{U}_{\text {abs }} / \bar{U}_{\text {abs, ref. }}\end{array}$ \\
\hline \multirow[t]{4}{*}{2} & I & 48.02 & 2.51 & 7.03 & 0.165 & 2.89 & \multirow[t]{4}{*}{$2.83( \pm 0.14)$} \\
\hline & II & 47.58 & 0 & 7.00 & $>0.268$ & $>2.03$ & \\
\hline & III & 47.45 & 18.51 & 2.92 & 0.171 & 2.68 & \\
\hline & IV & 47.31 & 18.74 & 3.99 & 0.122 & 2.93 & \\
\hline \multirow[t]{4}{*}{4} & I & 47.64 & 5.84 & 7.03 & 0.131 & 2.30 & \multirow{4}{*}{$2.17( \pm 0.36)$} \\
\hline & II & 47.59 & 0.19 & 7.00 & 0.225 & 1.70 & \\
\hline & III & 47.45 & 22.90 & 2.92 & 0.135 & 2.12 & \\
\hline & IV & 47.45 & 21.41 & 3.99 & 0.106 & 2.56 & \\
\hline \multirow[t]{4}{*}{6} & I & 47.55 & 12.40 & 7.03 & 0.092 & 1.62 & \multirow[t]{4}{*}{$1.64( \pm 0.24)$} \\
\hline & II & 47.45 & 1.72 & 7.00 & 0.177 & 1.34 & \\
\hline & III & 47.43 & 27.00 & 2.92 & 0.106 & 1.67 & \\
\hline & IV & 47.31 & 26.19 & 3.99 & 0.080 & 1.93 & \\
\hline
\end{tabular}

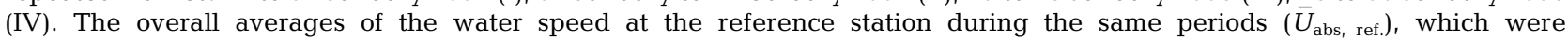
determined from ultrasonic flow meters, were 0.0571 (I), 0.01319 (II), 0.0638 (III), $0.0414 \mathrm{~m} \mathrm{~s}^{-1}$ (IV) 


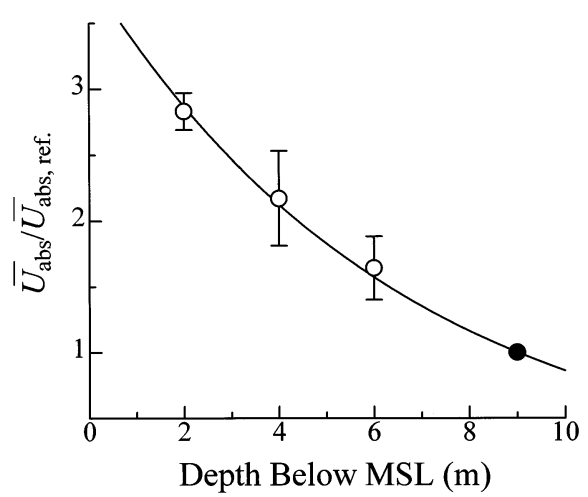

Fig. 8. Ratio of the overall average water speeds $\left(\bar{U}_{\text {abs }}\right)$ on the transplant slope to that at the reference station $\left(\bar{U}_{\mathrm{abs}, \text { ref. }}\right)$. Error bars represent $1 \mathrm{SD}$. Solid line represents least squares regression equation that intersects the point $(\bullet ; h=9 \mathrm{~m}, f=$ 1): $f(h)=\mathrm{e}^{-0.1506(h-9)},\left(\mathrm{r}^{2}=0.999\right)$

(Fig. 3). In that period the maximum observed $U_{\text {rms, ref. }}$ was $0.12 \mathrm{~m} \mathrm{~s}^{-1}$ and the lowest tide was $0.9 \mathrm{~m}$ below MSL at the nearest tide station, Ayukawa $\left(38^{\circ} 18^{\prime} \mathrm{N}\right.$, $\left.141^{\circ} 31^{\prime} \mathrm{E}\right)$. Therefore Eq. (11) gives the maximum temporal $f$ at the transplant depths of 2,4 and $6 \mathrm{~m}$ as 3.29, 2.43, and 1.80, respectively. $T_{\mathrm{s}}$ observed off Enoshima Island during the first high-wave period was $\sim 7.0 \mathrm{~s}$, and $\Delta \tau=7200 \mathrm{~s}$. Consequently, the maximum water speeds encountered by the transplants at the 2,4 , and $6 \mathrm{~m}$ depths until the first observations of survivorship were estimated from Eq. (2) with Eq. (3) as 1.49, 1.10, and $0.81 \mathrm{~m} \mathrm{~s}^{-1}$, respectively. These preliminary estimates coupled with the first observed survivorships might predict that the dislodgement velocity for the 'sheltered' plants was as high as $1 \mathrm{~m} \mathrm{~s}^{-1}$.

\section{Tolerance to oscillating flow}

As found in the transplant experiment, 'sheltered' and 'exposed' Laminaria japonica showed marked differences in their tolerance to water motion in the laboratory tank (Fig. 9). In the increasing velocity amplitude $(\hat{U})$ of regularly oscillating flows, 'sheltered' plants were initially dislodged even at $0.4 \mathrm{~m} \mathrm{~s}^{-1}$, and then half of them were removed at 0.8 to $0.9 \mathrm{~m} \mathrm{~s}^{-1}$. This average dislodgement velocity for 'sheltered' plants was consistent with the above-mentioned prediction from the field transplant experiment. The dislodgement of 'sheltered' plants occurred normally in the first few minutes of each run with a given $\hat{U}$ and never after $\sim 20 \mathrm{~min}$. In contrast, all 'exposed' plants persisted up to $\hat{U}=1.1 \mathrm{~m} \mathrm{~s}^{-1}$, losing the tattered distal end of the blade.

Note that in the sinusoidal oscillatory flow with a period $(T)$ of $12.8 \mathrm{~s}, \hat{U}$ of $>0.6$ to $0.8 \mathrm{~m} \mathrm{~s}^{-1}$ was required to fully extend plants tested of about

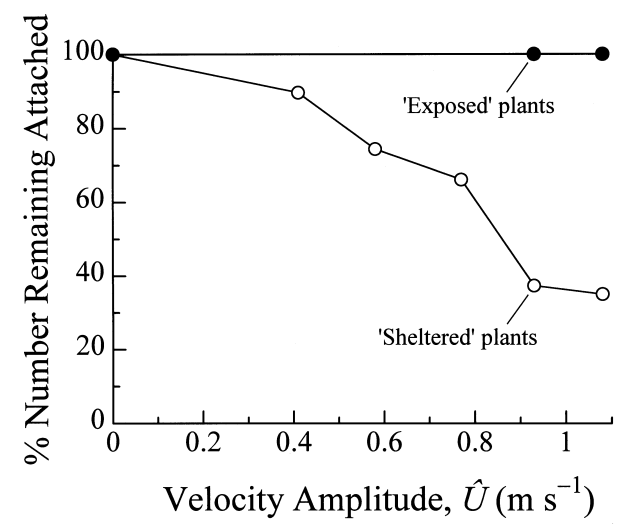

Fig. 9. Survivorships of the 'sheltered' $(O ; N=59)$ and the 'exposed' $(\bullet ;=30)$ Laminaria japonica in sinusoidal oscillatory flows with the cyclic period of $12.8 \mathrm{~s}$ in the laboratory flow tank

$1.5 \mathrm{~m}$ length in both directions of the flow. At this critical $\hat{U}$, the diameter of the oscillatory motion of the fluid particles, which was given as $\hat{U} T / \pi$, was 2.4 to $3.3 \mathrm{~m}$, indicating that the free end of the plants moved as far as the water particles. Also, at $\hat{U}<1.1 \mathrm{~m} \mathrm{~s}^{-1}$ the plants appeared too long to stretch out in 1 direction from their slack postures in the opposite direction while the water velocity increased from 0 to a maximum.

\section{Plant morphology}

Morphological measurements showed that 'sheltered' Laminaria japonica plants formed narrow, thin, flat blades and long, thick stipes while the 'exposed' ones formed wide, thick, undulate blades and short, thin stipes (Table 4). The blade length:width ratio for the 'exposed' plants was about twice as large as that for the 'sheltered' ones. The undulation index indicated that the blade margin was corrugated for the 'sheltered' plants while nearly flat for the 'exposed' plants (Fig. 10). However, the index indicated that the blade undulation

Table 4. Blade morphologies (mean $\pm \mathrm{SD}$ ) of the 'sheltered' $(N=59)$ and 'exposed' $(N=30)$ Laminaria japonica used in the laboratory flow-tolerance experiment. $p$ values are those of the Mann-Whitney $U$-test comparison

\begin{tabular}{|lccll|}
\hline Parameters & Sheltered & Exposed & p value \\
\hline Blade length $(\mathrm{m})$ & $1.47 \pm 0.40$ & $1.67 \pm 0.45$ & $<0.02$ \\
Blade width $(\mathrm{cm})$ & $9.6 \pm 2.4$ & $6.2 \pm 1.5$ & $<0.0001$ \\
Blade area $\left(10^{-2} \mathrm{~m}^{2}\right)$ & $9.86 \pm 3.60$ & $7.19 \pm 2.57$ & $<0.0002$ \\
Blade thickness $(\mathrm{mm})$ & $1.231 \pm 0.220$ & $1.421 \pm 0.229$ & $<0.0005$ \\
Stipe length $(\mathrm{cm})$ & $13.05 \pm 3.13$ & $11.33 \pm 2.19$ & $<0.005$ \\
Stipe diameter $(\mathrm{mm})$ & $6.96 \pm 1.05$ & $6.66 \pm 0.62$ & $<0.03$ \\
Blade length:width ratio & $16.1 \pm 5.3$ & $28.5 \pm 10.4$ & $<0.0001$ \\
& & & \\
\hline
\end{tabular}




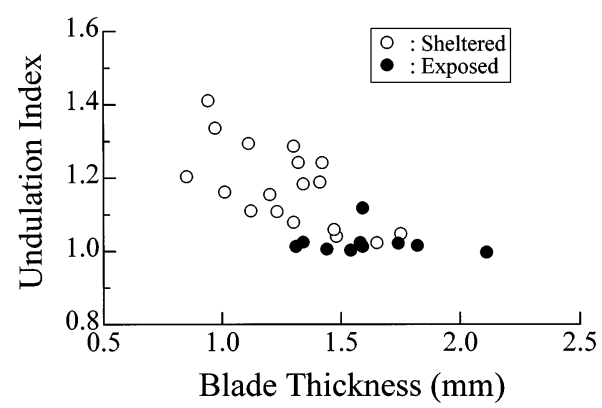

Fig. 10. Comparison between the undulation indices of the 'sheltered' (০) and the 'exposed' (•) Laminaria japonica plotted against the blade thickness

for the 'sheltered' plants decreases with the increasing blade thickness (Kendall's test, $\mathrm{p} \ll 0.001$ ).

\section{Attachment strength}

The attachment strength for the 'sheltered' and 'exposed' Laminaria japonica plants sent to HCFES was plotted against the holdfast wet mass in Fig. 11. The development in the holdfast led to a significant increase in the attachment strength for the 'exposed' plants (Student's $t=3.63$, df $=10, \mathrm{p}<0.003$ ) but not for the sheltered ones (Student's $t=0.057, \mathrm{df}=9, \mathrm{p}=0.3$ ). The holdfast was branched, forming fibrous haptera. Generally, the haptera of the 'exposed' plants extended radially and attached firmly to the substrate, while the haptera of the 'sheltered' plants were curved and frequently failed to make contact with the substratum.

Field measurements provided evidence for the view that the attachment strength was little influenced by

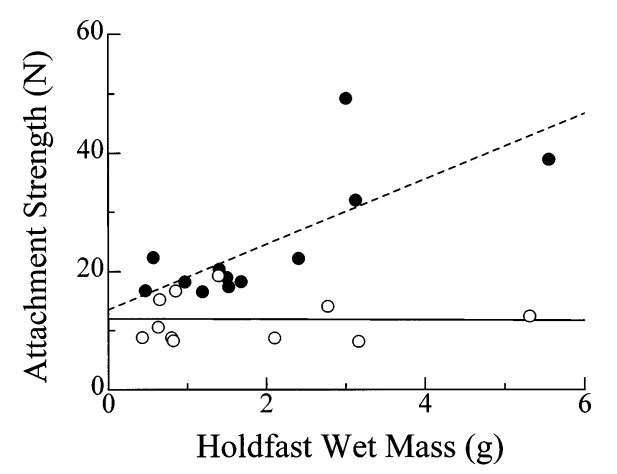

Fig. 11. Relationships between attachment strength $(\mathrm{N})$ and holdfast wet mass ( $\mathrm{g}$ ) for the 'sheltered' (o) and the 'exposed' (•) Laminaria japonica. Solid line represents least squares regression for the 'sheltered' plants: attachment strength $=$ $12.02-0.0446 \times$ (holdfast mass),$\left(r^{2}=0.000295, N=11\right.$, not significant at $p=0.05)$. Dashed line represents regression for the 'exposed' plants: attachment strength $=13.57+5.52 \times$ (holdfast mass), $\left(\mathrm{r}^{2}=0.568, N=12, \mathrm{p}<0.005\right)$ the experimental exposure of plants to air, the smooth surface of PVC substrata and very high densities of plants in cultivation. The 'sheltered' and 'exposed' plants sent to HCFES were similar in attachment strength to the corresponding plants kept continuously submerged at the culture platforms, respectively (Table 5). In addition, the attachment strength of the 'sheltered' plants was comparable with that of wild plants of a similar size attaching sparsely to a rocky substratum, which was exposed to similar intensities of water motion (Table 6).

\section{Drag}

Although the drag coefficients, $C_{\mathrm{d}}$, for Laminaria japonica with various blade forms spread sparsely when preliminarily plotted against the velocity, they separated into 2 different groups when plotted against the Reynolds number, Re (Fig. 12). Excluding the data of 2 plants that extended over the 2 groups, a power curve regression on the log-log transformed data from the higher drag group is

$$
C_{\mathrm{d}}=651 R e^{-0.715}
$$

and that from the lower drag group is

$$
C_{\mathrm{d}}=47.87 R e^{-0.574}
$$

Table 5. Field measurements (mean \pm SD) of attachment strength for Laminaria japonica plants growing on PVC plates at the sheltered and exposed culture stations and for the wild plants growing on rocky bottom area at Site $M$ shown in Fig. 1A. Plants tested had similar size blade lengths of 1.5 to $2.0 \mathrm{~m}$

\begin{tabular}{|lrl|}
\hline Plants & $N$ & Attachment strength \\
\hline Sheltered cultured & 8 & $16.4 \pm 5.7$ \\
Exposed cultured & 10 & $49.1 \pm 16.3$ \\
Wild & 10 & $19.9 \pm 7.5$ \\
\end{tabular}

Table 6. Comparison of $\bar{U}_{\mathrm{abs}}$ between the sheltered (S) and exposed (E) culture stations and natural site (M) at which measurements were made on the attachment strength of Laminaria japonica. The period and $\bar{U}_{\mathrm{abs} \text {, ref. }}$ are the same as described in Table 3

\begin{tabular}{|lccc|}
\hline Period & Site & $\bar{U}_{\mathrm{abs}}\left(\mathrm{m} \mathrm{s}^{-1}\right)$ & $\bar{U}_{\mathrm{abs}} / \bar{U}_{\mathrm{abs}, \text { ref. }}$ \\
\hline III & $\mathrm{S}$ & 0.074 & 1.16 \\
& $\mathrm{E}$ & 0.117 & 1.83 \\
$\mathrm{~V}$ & $\mathrm{M}$ & 0.066 & 1.04 \\
& $\mathrm{~S}$ & 0.055 & 1.32 \\
& $\mathrm{E}$ & 0.092 & 2.21 \\
& $\mathrm{M}$ & 0.050 & 1.21 \\
\hline
\end{tabular}




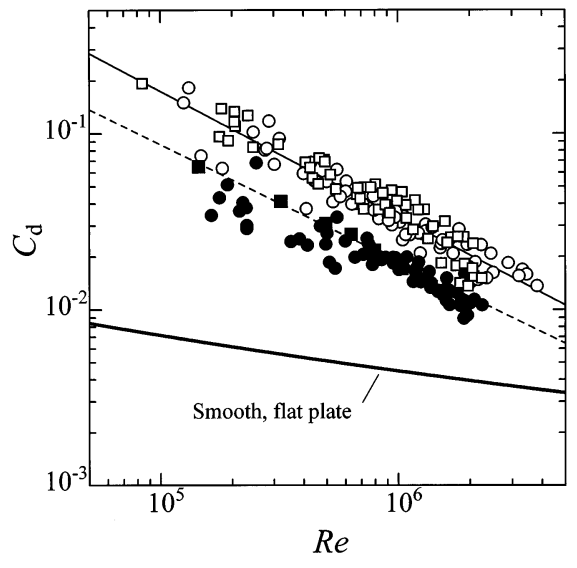

Fig. 12. Drag coefficients $\left(C_{\mathrm{d}}\right)$ of Laminaria japonica with various blade morphologies plotted against the Reynolds number $(R e)$. Measurements were made in different water velocities ( 0.2 to $1.9 \mathrm{~m} \mathrm{~s}^{-1}$ ) for 18 plants collected from natural habitats with different degrees of wave exposure (circles) and for 9 plants cultured in laboratory flow tank (squares). Upper solid line is least squares regression for the higher drag group of 9 natural (O) and 8 cultured ( $\square$ ) plants: $\ln C_{\mathrm{d}}=6.479-$ $0.7148 \ln R e,\left(\mathrm{r}^{2}=0.903, N=120, \mathrm{SE}=0.193\right)$. Middle dashed line is least squares regression for the lower drag group of 9 natural (๑) and 1 cultured ( $\square$ ) plants: $\ln C_{\mathrm{d}}=3.869-0.574 \ln R e$, $\left(\mathrm{r}^{2}=0.857, N=72, \mathrm{SE}=0.170\right)$. Lower bold line represents $C_{\mathrm{d}}$ of a smooth, flat plant oriented parallel to the flow, which is described by Eq. (8)

Most of the slender plants with the exposed blade morphology belonged to the lower drag group whereas most of the plants with the sheltered blade morphology from the natural habitats and all except 1 from culture belonged to the higher drag group. The sheltered blade morphology appeared to increase the drag by the waving of the corrugated blade margins rather than the flapping of the entire blade in unidirectional flow. $C_{\mathrm{d}}$ for both drag groups of Laminaria japonica were much larger than that for a rigid flat plate given by Eq. (8) but decreased toward it with increasing $\operatorname{Re}$ (Fig. 12).

Although 'exposed' and 'sheltered' plants used in the laboratory flow-tolerance experiment had similar blade areas, the drag on the 'exposed' plants, predicted by Eq. (13), was half as great as the drag on the 'sheltered' plants, predicted by Eq. (12) (Fig. 13).

\section{DISCUSSION}

\section{Adaptive mechanical tolerance and the initiating water velocity}

The results of this study suggest that development of mechanical tolerance in seaweeds is initiated by a crit- ical level of water motion. Laminaria japonica can achieve such mechanical tolerance by the formation of a flat, narrow blade and effective attachment.

Similar to kelps such as Laminaria digitata (Sundene 1962, 1964), Saccorhiza polyschides (Norton 1969), L. longicruris (Gerard \& Mann 1979) and Nereocystis luetkeana (Koehl \& Alberte 1988), L. japonica formed thick, narrow and flat blades when growing at the exposed station and thin, broad and undulate blades at the sheltered station. The flat blade morphology of 'exposed' plants may result in a lower drag coefficient than the undulated blade morphology of 'sheltered' plants (Koehl \& Alberte 1988). In addition, the result of this study shows that the drag coefficient for algae decreases with the increasing Reynolds number or thallus length. Consequently, the predicted drag force on the 'exposed' L. japonica was only half as great as that on the 'sheltered' plants.

The mechanical failure in the plants occurred in the adhesion of the holdfast to the substratum or in the tensile tolerance of the blade, but never in the stipe. This is supported by observations of Laminaria japonica plants cast ashore. Attachment strength of L. japonica increased with the growth of the holdfast at the exposed station but not at the sheltered station, suggesting that the haptera will grow normally without physical stresses but require wave-induced stresses to attach firmly to the substratum. After the rapid growth period, however, the attachment strength seemed not to increase any further, because 'sheltered' L. japonica remaining at the deepest transplant site with lowest

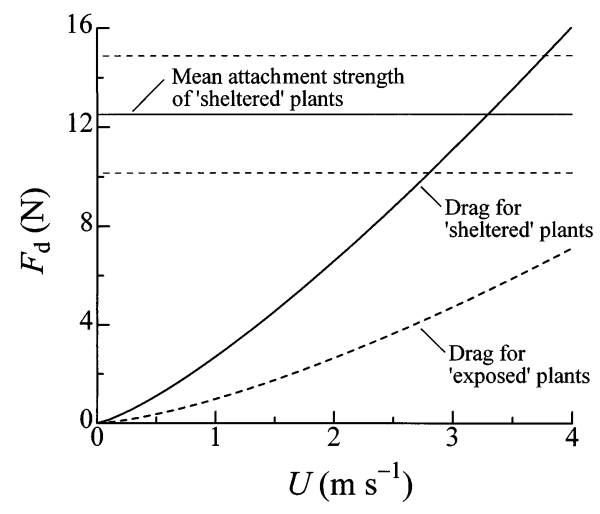

Fig. 13. Predicted drag $\left(F_{\mathrm{d}}\right)$ on the 'sheltered' and the 'exposed' Laminaria japonica with average blade area and length ( $l$ ) used in a laboratory flow-tolerance experiment. Drag for the 'sheltered' (solid curve) or the 'exposed' (dashed curve) plants is calculated from Eqs. (7), (9) \& (12) with $S(=2$ $\times$ blade area $)=0.1972$ or $0.1438 \mathrm{~m}^{2}, l=1.47$ or $1.67 \mathrm{~m}, \eta=1.1$ $\times 10^{-3} \mathrm{~N} \mathrm{~s} \mathrm{~m}^{-2}$ and $\rho=1025 \mathrm{~kg} \mathrm{~m}^{-3}$. Horizontal solid line represents the mean attachment strength of the plants, and horizontal dashed lines represents the $95 \%$ confidence limits $(=12.51 \pm 2.36 \mathrm{~N})$ of the mean 
water motion for $23 \mathrm{~d}$ were completely removed by the subsequent higher waves.

Despite marked differences in the tolerance to flow between the 'sheltered' and 'exposed' Laminaria japonica plants, the difference in water motion between their cultivation sites was unexpectedly small, approximating $0.05 \mathrm{~m} \mathrm{~s}^{-1}$ in $U_{\text {rms. }}$. This indicated the presence of a threshold in the degree of water motion for developing adaptive mechanical strength. For example, the occurrence frequency of $U_{\mathrm{rms}}>0.20 \mathrm{~m} \mathrm{~s}^{-1}$ was $20 \%$ at the exposed culture station but only $3.2 \%$ at the sheltered culture station, indicating that the threshold water motion for L. japonica to develop into an exposed plant form might occur around $0.20 \mathrm{~m} \mathrm{~s}^{-1}$ in $U_{\text {rms }}$. This expected critical $U_{\text {rms }}$-value corresponds to when $10 \%$ of the Rayleigh-distributed velocity amplitude exceeds $\sim 0.43 \mathrm{~m} \mathrm{~s}^{-1}$ (see Appendix B). In the cultivation conducted in the laboratory flow tank, $L$. japonica never stretched completely in the sinusoidal oscillatory flow when velocity amplitude was $<0.21 \mathrm{~m}$ $\mathrm{s}^{-1}$ and the period $12 \mathrm{~s}$ and formed blades of sheltered type, even when they were short. This is consistent with the threshold velocity expected in the field.

The question arises whether this threshold velocity applied sufficient tension to form the exposed blade morphology and increase the attachment strength. For example, because the free end of a plant moves as far as the fluid particles, a sinusoidal orbital velocity with the above-described amplitude of $0.43 \mathrm{~m} \mathrm{~s}^{-1}$ and the period of $10 \mathrm{~s}$ will displace the blade tip only $1.37 \mathrm{~m}$ in the direction of flow. This displacement was insufficient to fully extend most of the cultured plants, which were longer than $1 \mathrm{~m}$. Therefore an alternative or additional factor might be important: plants grown at the exposed platforms occasionally encountered waveinduced unidirectional water flow, which might have exceeded $0.2 \mathrm{~m} \mathrm{~s}^{-1}$ and extended the blade further (Fig. 2).

The complex nature of the field water motion rendered the expected threshold velocity of adaptive mechanical tolerance unclear. To elucidate this, a practical methodology to measure water velocity is required, as described here. The gypsum-block method developed in this study could provide an adequately accurate measurement of the average water speed during a period of time. This simple, inexpensive instrument, coupled with a high-frequency flow meter, successfully provided a prediction of the dislodgement velocity for the 'sheltered' Laminaria japonica in the field, which reasonably agreed with that observed in the laboratory. The results indicate that the method might have the potential for reasonably accurate measurements of spatial and temporal variations in wave-induced water motion in a given subtidal area.

\section{Dislodgement velocity}

The most simple method to predict the water velocity at which a plant begins to be dislodged is based on the assumption that a plant is fully extended and stationary in the direction of flow when the oscillatory water velocity reaches a maximum. Under this assumption, the dislodgement velocity is given simply as the velocity at which the drag predicted from Eq. (7) equals the attachment strength. In the laboratory experiment on the tolerance to oscillating flow, the predicted dislodgement velocity of 'sheltered' Laminaria japonica tested was 2.95 to $3.97 \mathrm{~m} \mathrm{~s}^{-1}$ within the $95 \%$ confidence interval of the mean attachment strength (Fig. 13). This prediction was considerably higher than the observed $\hat{U}$ of 0.8 to $0.9 \mathrm{~m} \mathrm{~s}^{-1}$ at which $50 \%$ of the 'sheltered' plants were dislodged. The difference between predicted and observed results is even more surprising if the 'going with flow' motion (Koehl 1986) and 'shading' effect by neighbouring plants are taken into consideration.

In addition to drag, a plant in unsteady flows might be subject to acceleration reaction forces. The accelerational force on an object is written as

$$
F_{\mathrm{a}}=C_{\mathrm{M}} \rho V(\mathrm{~d} U / \mathrm{d} t)
$$

where $V$ is the volume of the object, $C_{M}$ the inertia coefficient, and $\mathrm{d} U / \mathrm{d} t$ the acceleration of the fluid. In rocky intertidal sites the acceleration might be extremely high (>100 $\mathrm{m} \mathrm{s}^{-2}$ ) and the consequent large accelerational force on organisms has been predicted to be a critical factor in their wave-induced mortality (Denny 1985, Gaylord et al. 1994, Blanchette 1997, Gaylord 1999). In subtidal sites, however, such high acceleration is very unlikely to occur, and at least the accelerational force might not be sufficient to account for the dislodgement observed in this study. In the laboratory flow-tolerance experiment, the maximum acceleration given as $2 \pi \hat{U} / T$ was only $0.53 \mathrm{~m} \mathrm{~s}^{-2}$ even at the highest velocity amplitude which removed more than $50 \%$ of the 'sheltered' Laminaria japonica plants. Again, provided that the thallus is fully extended parallel to flow, the value of $C_{\mathrm{M}} V$ on the right hand side of Eq. (14) would be small. In this case, the $C_{\mathrm{M}} V$ can be interpreted as the entire volume of the fluid both displaced by an object and stagnated along with it. For example, given the $C_{\mathrm{M}} V$ for the mean size of the 'sheltered' plants as $0.1 \mathrm{~m}^{2}$ (blade area) $\times 0.03 \mathrm{~m}$ (twice the tentative estimate of the stagnant film thickness on a blade surface), the maximum accelerational force on the plant, predicted by Eq. (14), is only $1.6 \mathrm{~N}$. This is lower than the maximum drag in the same flow conditions (Fig. 13). This low estimate suggests that hydrodynamic force due solely to the acceleration of the fluid is merely a minor factor in the observed dislodgement. 
Previous studies described 2 other mechanisms increasing the risk of flow-induced breakage: entanglement with drifting plants (Koehl \& Wainwright 1977 , Seymour et al. 1989, Friedland \& Denny 1995) and fatigue failure due to repeated wave forces (Santelices et al. 1980). However, neither mechanisms explain the above-mentioned observed low tolerance to oscillatory flow, because entanglement rarely occurs in the nonbuoyant, strap-like structure of Laminaria japonica, and because fatigue failure generally requires a considerably large number of repeated deformations. The dislodgement of the 'sheltered' plants normally occurred in the first few minutes of the experimental oscillating flow.

The failure to explain the observed dislodgement thus addresses a critical problem in the quasi-steady approach as well as the necessity of analyzing the dynamic behavior of large algae. What has the potential for solving this problem is a numerical engineering model such as that of Friedland \& Denny (1995) and Utter \& Denny (1996) applied to the wave-induced motion of buoyant kelps. Their models treat a plant body as a system of particles connected with elastic springs in line, and can thereby account for the dynamic behavior in a given flow field. However, the model should be improved to account for 2 important mechanisms, bending stiffness and viscous friction.
The bending stiffness of a stipe attached upright to the substratum might be necessary to predict the bending moment due to external forces at the attachment base. A plant with a less flexible stipe is less bent. The consequent larger distance from the bottom to the point of the force application results in a larger bending moment at the base. This bending moment might produce stress concentration at the periphery of holdfast-substratum interface. In addition, unlike the ideal elastic springs in the model, most plant materials exhibit properties of both solids and fluids, termed viscoelasticity (Niklas 1992). The movement of viscoelastic materials is resisted not only by the elastic force, but also by the viscous friction. In a crude sense this viscous friction is proportional to the rate of deformation. Thus the abrupt extension of a stipe, which may occur when the thallus is suddenly strained and stopped by the stationary holdfast while moving with the flow, might be damped by the consequent high viscous friction.

In particular, because this abrupt halt causes an impulsive force, the viscoelasticity should be adequately described in the model. An object and associated water moving with the surrounding fluid possess momentum. This momentum can apply inertial force to the body when the motion is slowed by its elastic stipe. The shorter the time that it takes for an object to come

Appendix A. Definitions of symbols

\begin{tabular}{|c|c|c|c|}
\hline$C_{\mathrm{d}}$ & Drag coefficient & $U$ & Instantaneous water velocity $\left(\mathrm{m} \mathrm{s}^{-1}\right)$ \\
\hline$C_{\mathrm{M}}$ & Inertia coefficient & $U_{\mathrm{m}}$ & $\begin{array}{l}\text { Magnitude of mean water velocity vector } \\
\left(\mathrm{m} \mathrm{s}^{-1}\right)\end{array}$ \\
\hline $\begin{array}{l}a_{0} \\
f(h)\end{array}$ & Ratio of $U$ at depth of $h$ on the transplant & $\hat{U}$ & Water velocity amplitude $\left(\mathrm{m} \mathrm{s}^{-1}\right)$ \\
\hline$F_{\mathrm{a}}$ & $\begin{array}{l}\text { slope to } U_{\mathrm{rms}} \text {, ref. } \\
\text { Acceleration reaction }(\mathrm{N})\end{array}$ & $U_{\text {abs }}$ & $\begin{array}{l}\text { Temporal average of absolute water velocity } \\
\left(\mathrm{m} \mathrm{s}^{-1}\right)\end{array}$ \\
\hline$F_{\mathrm{d}}$ & Drag (N) & $\bar{U}_{\text {abs }}$ & $\begin{array}{l}\text { Overall average of } U_{\text {abs }} \text { during measurement } \\
\text { period }\left(\mathrm{m} \mathrm{s}^{-1}\right)\end{array}$ \\
\hline$\frac{h}{h}$ & Temporal water depth (m) & $<\hat{U}_{\max }>$ & Most probable value of maximum $\hat{U}\left(\mathrm{~m} \mathrm{~s}^{-1}\right)$ \\
\hline $\begin{array}{l}h \\
H\end{array}$ & $\begin{array}{l}\text { Mean water depth (m) } \\
\text { Significant wave height (m) }\end{array}$ & $U_{\mathrm{rms}}$ & Root-mean-square water velocity $\left(\mathrm{m} \mathrm{s}^{-1}\right)$ \\
\hline $\begin{array}{l}\mu_{\mathrm{s}} \\
1\end{array}$ & Characteristic length of object (m) & $U_{\text {rms }}^{\prime}$ & $\begin{array}{l}\text { Root-mean-square water velocity fluctuations } \\
\left(\mathrm{m} \mathrm{s}^{-1}\right)\end{array}$ \\
\hline$m$ & Mass of gypsum block (g) & $\hat{U}_{\mathrm{rms}}$ & Root mean square of $\hat{U}\left(\mathrm{~m} \mathrm{~s}^{-1}\right)$ \\
\hline $\begin{array}{l}m_{0}, m_{\tau} \\
N\end{array}$ & $\begin{array}{l}m \text { at immersion periods of } 0 \text { and } \tau(\mathrm{g}) \\
\text { Sample size }\end{array}$ & $\left(u_{i}, v_{i}\right)$ & $\begin{array}{l}\text { ith 2-dimensional instantaneous water } \\
\text { velocities }\left(\mathrm{m} \mathrm{s}^{-1}\right)\end{array}$ \\
\hline$p(\hat{U})$ & Probability density of $\hat{U}$ & $(\bar{u}, \bar{v})$ & Mean water velocity vector $\left(\mathrm{m} \mathrm{s}^{-1}\right)$ \\
\hline$P\left[\hat{U}>\hat{U}_{\mathrm{p}}\right]$ & Probability that $\hat{U}>\hat{U}_{\mathrm{p}}$ & $\left(u_{i}^{\prime}, v_{i}^{\prime}\right)$ & $\left(u_{i}-\bar{u}, v_{i}-\bar{v}\right)\left(\mathrm{m} \mathrm{s}^{-1}\right)$ \\
\hline$R$ & $\begin{array}{l}\text { Temporal rate of reduction in the thickness of } \\
\text { gypsum block }\left(\mathrm{mm} \mathrm{d}^{-1}\right)\end{array}$ & $U_{\text {abs, ref. }}$ & $\begin{array}{l}U_{\text {abs' }}, \bar{U}_{\text {abs, }}, U_{\text {rms }} \text { and } U_{\text {rms }}^{\prime} \text { at the reference } \\
\text { station }\left(\mathrm{m} \mathrm{s}^{-1}\right)\end{array}$ \\
\hline $\bar{R}$ & $\begin{array}{l}\text { Overall average of } R \text { during the measure- } \\
\text { ment period }\left(\mathrm{mm} \mathrm{d}^{-1}\right)\end{array}$ & $\begin{array}{l}U_{\mathrm{rms}, \text { ref. }} \\
U_{\mathrm{rms} \text {, ref. }}^{\prime}\end{array}$ & \\
\hline $\operatorname{Re}$ & Reynolds number & $V$ & Volume of object $\left(\mathrm{m}^{3}\right)$ \\
\hline$S$ & Surface area exposed to fluid $\left(\mathrm{m}^{2}\right)$ & $\eta$ & Dynamic viscosity of fluid $\left(\mathrm{N} \mathrm{s} \mathrm{m}^{-2}\right)$ \\
\hline$t$ & Time (s) & $\theta$ & Phase angle (rad) \\
\hline$T$ & Period of a wave (s) & $\rho$ & Density of fluid $\left(\mathrm{kg} \mathrm{m}^{-3}\right)$ \\
\hline$T_{\mathrm{m}}$ & Average of $T(\mathrm{~s})$ & $\tau$ & Immersion period of gypsum block (d) \\
\hline$T_{\mathrm{s}}$ & Significant wave period (s) & $\Delta \tau$ & Burst time interval of recordings (s) \\
\hline
\end{tabular}


to a complete halt after beginning to be slowed, the higher the peak tension. This working period can be very short. The consequent peak force thus can be considerable. To some extent long Laminaria japonica plants might lessen this peak force by the process of reorientation: a blade extended by a flow in 1 direction begins to reverse at the basal portion connected to the upright stipe when the flow is reversed, and then the resulting blade hollow moves in the opposite direction bearing the flow resistance until it is fully extended. Nevertheless, the above-mentioned impulsive forces should occur on the attachment base as long as a mov- ing object comes to a sudden halt. Although Denny et al. (1998) discussed the dynamics of marine plants with a simplified model accounting for viscoelasticity, their viscoelastic behavior has, as yet, been little examined.

In conclusion, the observed dislodgement velocity of 'sheltered' Laminaria japonica plants was considerably lower than predicted from the conventional methods based on the hydrodynamic force on a stationary thallus stretched out in the direction of flow. This discrepancy might be attributable to unaccounted mechanisms associated with the dynamic behavior of the plants in oscillating flows.

Appendix B. Data procedure and estimating maximum water velocity amplitude

For velocity measurements from the ultrasonic flow meters at burst time intervals, 4 parameters were calculated: the rms of the water velocity $\left(U_{\text {rms }}\right)$, magnitude of the mean water velocity vector $\left(U_{\mathrm{m}}\right)$, rms of the water velocity fluctuations $\left(U_{\mathrm{rms}}^{\prime}\right)$, and average of the absolute water velocity $\left(U_{\text {abs }}\right)$. Let $\left(u_{i}, v_{i}\right), i=1, \ldots, N$ be the time series of 2-dimensional water velocities; the parameters are defined as:

and

$$
\begin{aligned}
& U_{\mathrm{rms}}=\left[\frac{1}{N} \sum_{i=1}^{N}\left(u_{i}^{2}+v_{i}^{2}\right)\right]^{1 / 2} \\
& U_{\mathrm{m}}=\left(\bar{u}^{2}+\bar{v}^{2}\right)^{1 / 2} \\
& U_{\mathrm{rms}}^{\prime}=\left[\frac{1}{N} \sum_{i=1}^{N}\left(u_{i}^{\prime 2}+v_{i}^{\prime 2}\right)\right]^{1 / 2}
\end{aligned}
$$

$$
U_{\mathrm{abs}}=\frac{1}{N} \sum_{i=1}^{N}\left(u_{i}^{2}+v_{i}^{2}\right)^{1 / 2}
$$

where $(\bar{u}, \bar{v})$ and $\left(u_{i}^{\prime}, v_{i}^{\prime}\right)$ are the mean and fluctuating velocity components, into which the instantaneous water velocity is resolved as:

and

$$
u_{i}=\bar{u}+u_{i}^{\prime}
$$

$$
V_{i}=\bar{V}+V_{i}^{\prime}
$$

As well known, there is the relationship among $U_{\mathrm{rms}}, U_{\mathrm{m}}$ and $U_{\mathrm{rms}}^{\prime}$ :

$$
U_{\mathrm{rms}}^{2}=U_{\mathrm{m}}^{2}+U_{\mathrm{rms}}^{\prime 2}
$$

Eq. (B7) describes that the time-averaged kinetic energy of the fluid, which is proportional to the time-averaged drag force, is identical to the sum of the kinetic energy of the mean velocity component and that of the fluctuating velocity components.

Provided that real random waves consist of many component sine waves with different frequencies and directions, the rms of the fluctuating velocity amplitude $\hat{U}_{\text {rms }}$ (a velocity amplitude $\hat{U}$ is here defined as a peak fluctuating water speed minus $U_{\mathrm{m}}$ ):

$$
\hat{U}_{\mathrm{rms}}=2^{1 / 2} U^{\prime}{ }_{\mathrm{rms}}
$$

The velocity amplitude in a subtidal site might be generally distributed according to the Rayleigh probability density function as the surface wave heights (Soulsby 1987). The Rayleigh probability density function is

$$
p(\hat{U})=\frac{2 \hat{U}}{\hat{U}_{\mathrm{rms}}^{2}} \exp \left[-\left(\frac{\hat{U}}{\hat{U}_{\mathrm{rms}}}\right)^{2}\right]
$$

If $\hat{U}_{\text {rms }}$ is obtained from observations through Eq. (B8), the integration of Eq. (B9) gives the probability that $\hat{U}$ exceeds some value $\hat{U}_{\mathrm{p}}$ as:

$$
P\left[\hat{U}>\hat{U}_{\mathrm{p}}\right]=\exp \left[-\left(\frac{\hat{U}_{\mathrm{p}}}{\hat{U}_{\mathrm{rms}}}\right)^{2}\right]
$$

From Eq. (B10), we obtain, for example, that $\mathrm{p}=0.1$ for $\hat{U}_{\mathrm{p}} / \hat{U}_{\mathrm{rms}}=1.517$.

When the velocity amplitude is Rayleigh-distributed in a burst time interval $\Delta \tau$, the most probable value of the maximum velocity amplitude, denoted by $\left\langle\hat{U}_{\max }\right\rangle$, might be:

$$
<\hat{U}_{\max }>=\left[\ln \left(\Delta \tau / T_{\mathrm{m}}\right)\right]^{1 / 2} \hat{U}_{\mathrm{rms}}
$$

where $T_{\mathrm{m}}$ is the average period of waves. By analogy to the wave height distribution, Eq. (B11) might be a good approximation for $\Delta \tau / T_{\mathrm{m}}>50$ (Longuet-Higgins 1952). The mean period is empirically related with the significant wave period $\left(T_{\mathrm{s}}\right)$ (Goda 1985) as:

$$
T_{\mathrm{s}} \approx 1.2 T_{\mathrm{m}}
$$

The nearshore water motion is driven primarily by tide and waves. Generally, unbroken waves little affect $U_{\mathrm{m}}$ values because the wave-induced water velocities observed at a stationary point amount to nearly 0 due to their alternative fluctuations, even in storms. Therefore, outside the surf zone, $U_{\mathrm{m}}$ corresponds to the tidal current, while $U_{\text {rms }}^{\prime}$ represents the intensity of the wave-induced oscillatory water motion. In shallow waters such as the surf zone, however, $U_{\mathrm{m}}$ may be due primarily to waves but little to the tide (Fredsøe \& Deigaard 1992). This wave-driven current results from the wave momentum flux termed the radiation stresses, and reaches maximal value near wave breaking point but decreases towards zero at a shore (Fredsøe \& Deigaard 1992). On the transplant slope in this study, the consequent large $U^{\prime}{ }_{\text {rms }}$ compared with $U_{\mathrm{m}}$ might lead to the approximation:

$$
U_{\mathrm{rms}}^{\prime} / U_{\mathrm{rms}} \approx 1
$$

Substituting Eqs. (B8), (B12) and (B13) into Eq. (B11) $<\hat{U}_{\max }>$ approximately becomes

$$
<\hat{U}_{\max }>\approx\left[2 \ln \left(1.2 \Delta \tau / T_{\mathrm{s}}\right)\right]^{1 / 2} U_{\mathrm{rms}}
$$


Appendix C. Relationship between mean water speed and rms water velocity

It might be reasonable to assume that the ratio of absolute water velocity between sites is stationary over time within a limited subtidal area. This assumption will provide a number of valuable estimates when gypsum blocks are employed together with a high-frequency flow meter. Nonetheless, neither theoretical nor empirical rules have been described yet with respect to the absolute water velocity in the field.

If the water velocity is sinusoidally fluctuated with an amplitude of $\hat{U}$ under the assumption of Eq. (B13), $U_{\text {abs }}$ and $U_{\text {rms }}$ are given as:

$$
\begin{aligned}
U_{\mathrm{abs}} & =\frac{1}{\Delta \tau} \int_{0}^{\Delta \tau}|\hat{U} \sin (2 \pi t / T-\theta)| \mathrm{d} t \\
& \approx \frac{2}{T} \int_{0}^{T / 2} \hat{U} \sin (2 \pi t / T) \mathrm{d} t=2 \hat{U} / \pi, \text { for } \Delta \tau \gg T
\end{aligned}
$$

and

$$
\begin{aligned}
U_{\mathrm{rms}} & =\left\{\frac{1}{\Delta \tau} \int_{0}^{\Delta \tau}[\hat{U} \sin (2 \pi t / T-\theta)]^{2} \mathrm{~d} t\right\}^{1 / 2} \\
& \approx\left\{\frac{4}{T} \int_{0}^{T / 4}[\hat{U} \sin (2 \pi t / T)]^{2} \mathrm{~d} t\right\}^{1 / 2}=\hat{U} / 2^{1 / 2}, \text { for } \Delta \tau \gg T
\end{aligned}
$$

where $\Delta \tau$ is the measurement period, $T$ the cyclic period, and $\theta$ the phase angle at $t=0$. Hence

$$
U_{\mathrm{rms}} / U_{\mathrm{abs}}=\pi /\left(2 \times 2^{1 / 2}\right)=1.11
$$

For random waves, the relationship between $U_{\mathrm{rms}}$ and $U_{\mathrm{abs}}$ was difficult to deduce theoretically, but the observations showed surprisingly close agreement with the above prediction from monochromatic velocity fluctuation (Fig. C1). Thus $f$ $\left(=U_{\text {rms }} / U_{\text {rms, ref. }}\right)$ is identical to $U_{\text {abs }} / U_{\text {abs, ref, }}$ where $U_{\text {abs, ref. is }} U_{\text {abs }}$ at the reference station. Although $f$ might be a non-linear

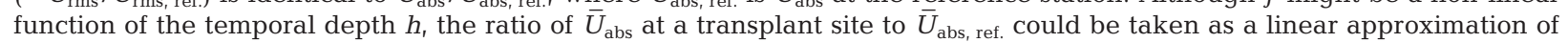
$f$, that is:

where $\bar{h}$ is the mean transplant depth.

$$
f(\bar{h}) \approx \bar{U}_{\mathrm{abs}} / \bar{U}_{\mathrm{abs}, \text { ref. }}
$$

Fig. C1. Relationship between rms water velocity $\left(U_{\text {rms }}\right)$ and mean absolute water velocity $\left(U_{\text {abs }}\right)$ observed at the sheltered $(N=$ $362)$ and the exposed $(N=495)$ culture stations and at the reference station $(N=1771)$ throughout the measurements with ultrasonic flow meters. Lines represent the theoretical relationship of Eq. (C3) for sinusoidal velocity fluctuation

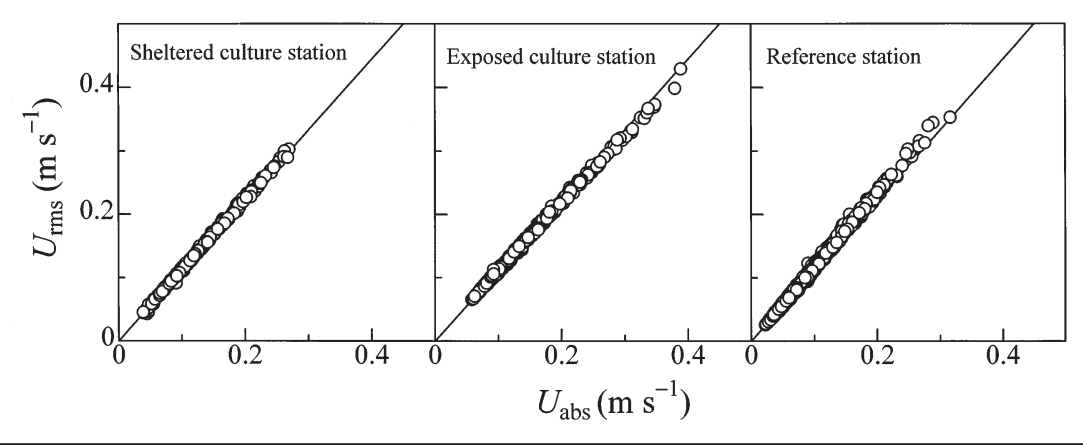

Appendix D. Estimation of average water speed from gypsum

Preliminary field tests showed that the shape of gypsum blocks approximately remained hemispherical while being dissolved in multidirectional, turbulent water flows. Thus it could be reasonably assumed that the dissolution rate $R$, defined as the rate of the reduction in thickness of the solid, is stationary over time and over the wetted solid surface under a constant flow condition. This is expressed by:

$$
\frac{\mathrm{d} m}{\mathrm{~d} t} \propto-m^{2 / 3} R
$$

where $m$ is the mass of the remaining gypsum, and $t$ the time. I then assumed that:

$$
U_{\text {abs }}=C\left(R-R_{0}\right)
$$

where $C$ is the coefficient and $R_{0}$ the dissolution rate in still water. Although $C$ and $R_{0}$ depend on water temperature and salinity, Eq. (D2) is substantially valid as long as the variations in these environmental parameters are small during the course of measurement (Thompson \& Glenn 1994). Then integrating Eq. (D1) with substitution of Eq. (D2) gives the overall average of the water speed during a measurement period ( $\left.\bar{U}_{\text {abs }}\right)$ as:

$$
\bar{U}_{\mathrm{abs}}=C\left(\bar{R}-R_{0}\right)
$$

with

$$
\bar{R}=\left(d_{0} / 2\right)\left[1-\left(m_{\tau} / m_{0}\right)^{1 / 3}\right] / \tau
$$

where $d_{0}$ is the initial diameter of the gypsum hemisphere, $\tau$ is the period of measurement, and $m_{0}$ and $m_{\tau}$ are the initial and final masses, respectively. 
Acknowledgements. I thank M. Seto, K. Kudo, S. Atobe and Y. Takaya for assistance in the laboratory experiment in Hokkaido. M. Fukuda assisted in the field work. R. Sasaki kindly allowed me to access his unpublished data on salinity. Offshore wave data were provided by the Japan Meteorological Agency. The study was supported by the Coastal Fishing Ground Improvement and Development Project through the Coastal Fisheries Development Division, Japan Fisheries Agency.

\section{LITERATURE CITED}

Blanchette CA (1997) Size and survival of intertidal plants in response to wave action: a case study with Fucus gardneri. Ecology 78:1563-1578

Boulding EG, Van Alstyne KL (1993) Mechanisms of differential survival and growth of two species of Littorina on wave-exposed and on protected shores. J Exp Mar Biol Ecol 169:139-166

Carrington E (1990) Drag and dislodgment of an intertidal macroalga: consequences of morphological variation in Mastocarpus papillatus Kützing. J Exp Mar Biol Ecol 139:185-200

Charters AC, Neushul M, Barilotti C (1969) The functional morphology of Eisenia arborea. Proc Intl Seaweed Symp 6:89-105

Denny MW (1985) Wave forces on intertidal organisms: a case study. Limnol Oceanogr 36:1171-1187

Denny MW, Gaylord B, Helmuth B, Daniel T (1998) The menace of momentum: dynamic forces on flexible organisms. Limnol Oceanogr 43:955-968

Doty MS (1971) Measurement of water movement in reference to benthic algal growth. Bot Mar 14:32-35

Fredsøe J, Deigaard R (1992) Mechanics of coastal sediment transport. World Scientific, Singapore

Friedland MT, Denny MW (1995) Surviving hydrodynamic forces in a wave-swept environment: consequences of morphology in the feather boa kelp, Egregia menziesii (Turner). J Exp Mar Biol Ecol 190:109-133

Gaylord B (1999) Detailing agents of physical disturbance: wave-induced velocities and accelerations on a rocky shore. J Exp Mar Biol Ecol 239:85-124

Gaylord B, Blanchette CA, Denny MW (1994) Mechanical consequences of size in wave-swept algae. Ecol Monogr 64:287-313

Gerard VA (1987) Hydrodynamic streamlining of Laminaria saccharina Lamour in response to mechanical stress. J Exp Mar Biol Ecol 107:237-244

Gerard VA, Mann KH (1979) Growth and production of Laminaria longicruris (Phaeophyta) populations exposed to different intensities of water movement. J Phycol 15:33-41

Glenn EP, Doty MS (1992) Water motion affects the growth rates of Kappaphycus alvarezii and related red seaweeds. Aquaculture 108:233-246

Goda Y (1985) Random seas and design of maritime structures. University of Tokyo Press, Tokyo

Hasegawa Y (1971a) Forced cultivation of Laminaria. Proc Intl Seaweed Symp 7:391-393

Hasegawa Y (1971b) Cultivation of Laminaria in Japan. Bull Hokkaido Reg Fish Res Lab 37:47-49

Editorial responsibility: Otto Kinne (Editor),

Oldendorf/Luhe, Germany
Kitching J, Muntz L, Ebling F (1966) The ecology of Lough Ine. XV. The ecological significance of shell and body forms in Nucella. J Anim Ecol 35:113-126

Koehl MAR (1986) Seaweeds in moving water: form and mechanical function. In: Givnish TJ (ed) On the economy of plant form and function. Cambridge University Press, Cambridge, p 603-634

Koehl MAR, Alberte RS (1988) Flow, flapping, and photosynthesis of Nereocystis luetkeana: a functional comparison of undulate and flat blade morphologies. Mar Biol 99: $435-444$

Koehl MAR, Wainwright SA (1977) Mechanical adaptations of a giant kelp. Limnol Oceanogr 22:1067-1071

Longuet-Higgins MS (1952) On the statistical distribution of the heights of sea waves. J Mar Res 11:245-266

Muss BJ (1968) A field method for measuring 'exposure' by means of plaster balls. A preliminary account. Sarsia 34: 61-68

Niklas KJ (1992) Plant biomechanics, an engineering approach to plant form and function. University of Chicago Press, Chicago

Norton TA (1969) Growth form and environment in SacCorhiza polyschides. J Mar Biol Assoc UK 49:1025-1045

Norton TA, Mathieson, AC, Neushul M (1982) A review of some aspects of form and function in seaweeds. Bot Mar 25:501-510

Palumbi SR (1986) How body plans limit acclimation: responses of a demosponge to wave force. Ecology 67: 208-214

Sanbonsuga Y, Torii S (1973) On the morphological characteristics of Laminaria japonica var. japonica studied by transplanting experiments. I. On the local forms of Laminaria japonica var. japonica. Bull Hokkaido Reg Fish Res Lab 39:61-82

Santelices B, Castilla JC, Cancino J, Schmiede P (1980) Comparative ecology of Lessonia nigrescens and Durvillaea antarctica (Phaeophyta) in Central Chile. Mar Biol 39: 119-132

Schlichting H (1968) Boundary-layer theory, 6th edn. McGraw-Hill, New York

Seymour RJ, Tegner MJ, Dayton PK, Parnell PE (1989) Storm wave induced mortality of giant kelp, Macrocystis pyrifera, in Southern California. Estuar Coast Shelf Sci 28: $277-292$

Soulsby RL (1987) Calculating bottom orbital velocity beneath waves. Coastal Eng 11:371-380

Sundene O (1962) Growth in the sea of Laminaria digitata sporophytes from culture. Nytt Mag Bot 9:5-24

Sundene O (1964) The ecology of Laminaria digitata in Norway in view of transplant experiments. Nytt Mag Bot 11: 83-107

Thompson TL, Glenn EP (1994) Plaster standards to measure water motion. Limnol Oceanogr 39:1768-1779

Trussell GC (1997) Phenotypic plasticity in the foot size of an intertidal snail. Ecology 78:1033-1048

Utter BD, Denny MW (1996) Wave-induced forces on the giant kelp Macrocystis pyrifera (Agardh): field test of a computational model. J Exp Biol 199:2645-2654

Yabu H (1964) Early development of several species of Laminariales in Hokkaido. Mem Fac Fish Hokkaido Univ 12: $1-72$

Submitted: December 9, 1999; Accepted: July 13, 2000

Proofs received from author(s): February 1, 2001 